\section{$\$$ Research Square}

Preprints are preliminary reports that have not undergone peer review.

They should not be considered conclusive, used to inform clinical practice,

or referenced by the media as validated information.

\title{
Influence of high-heeled shoe parameters on biomechanical performance of young female adults during stair ascent motion
}

jiangyinzi shang

Huashan Hospital Fudan University

Shuiqiang Zhang

Huzhou University

alan yan

University of Pittsburgh Medical Center

xin ma ( $\square$ maxinshhs@126.com)

Huashan Hospital Fudan University https://orcid.org/0000-0002-8608-8642

\section{Research article}

Keywords: high heeled shoe, stair ascent motion, kinematics, kinetic,finite element

Posted Date: February 17th, 2020

DOl: https://doi.org/10.21203/rs.2.23713/v1

License: () (1) This work is licensed under a Creative Commons Attribution 4.0 International License. Read Full License

Version of Record: A version of this preprint was published at Gait \& Posture on September 1st, 2020. See the published version at https://doi.org/10.1016/j.gaitpost.2020.07.065. 


\section{Abstract}

Background: No prior work has compared the biomechanical workload of stair ascent (SA) using shoes of different heel heights and heel types. Therefore, this study aimed to investigate the influence of high-heeled shoe (HHS) parameters on pelvis position, lower extremities kinematics, ground reaction force, and intern stress in young women during SA motion.

Methods: The participants were instructed to ascend a 3-step staircase, wearing HHSs of different heel heights and heel types, and the control group used a pair of flat shoes. By using finite element methodology, we investigated the influence of shoe parameters on metatarsal stress and metatarsal head loading during SA.

Results: As the heel height increased, increased ranges of ankle dorsiflexion-plantarflexion and pelvic rotation were observed. A thinner heel type displayed a larger pelvic forward tilt movement and 1 st peak vertical force, as well as a smaller 2nd peak vertical force. With higher heels, increased external rotation of the knee, inversion and plantar flexion, and flexion values of the knee were observed. Meanwhile, there was decreased external rotation of the pelvis, ankle eversion, varus, and dorsiflexion. Three major stance phases namely heel strike, midstance, and push off were simulated to investigate the biomechanical response of high-heeled walking. It was found that the contact pressure at plantar pressure and 1st metatarsal pressure intensified with flat shoes and reached their maximum at push off phase during locomotion.

Conclusion: To stabilize body posture during SA when wearing HHSs with a small heel base area, compensatory changes to drive an effective motor response include increasing pelvic range of motion in the transverse plane and sagittal plane, changing the joint angles of the lower extremities, and increasing metatarsal intern stress, may lead to clinical symptoms.

\section{Background}

Nowadays, high-heeled shoes (HHSs) are more preferred by women because of contemporary aesthetics. The American Podiatric Medical Association claimed that between $39 \%$ and $69 \%$ of women wear HHSs, with $40 \%$ of these women wearing them daily[1-3]. However, they may induce bone and musculoskeletal deformities, resulting in lower back discomfort, joint degeneration, forefoot pain, and hallux valgus[4-7].

Wearing HHSs alters ones kinematics and kinetics dramatically. Studies reported that HHSs reduced vertical balance and pelvic inclination angles with medium-to-large and large effects on static posture parameters[8]. Hollander et al. concluded that there was reduced pelvic tilt and increased transversal pelvic rotation due to HHS standing or walking[9]. By using radiographs, Osterhoff et al. found that HHSs had no effects on pelvic tilt and sacral slope in sagittal balance of the spine (kyphosis and lordosis angles) and the whole body[10]. Therefore, altered pelvic parameters may be interpreted as compensatory adaptations to HHSs, while muscular overuse, as well as postural load relieving may contribute to chronic side effects. For lower extremities, previous studies observed an increase in knee flexion and a decrease in ankle eversion associated with elevated heel heights while walking, and with higher peak vertical and anterior-posterior ground reaction forces (GRFs)[11]. Gu et al. described an increased range of knee abduction-adduction and hip flexion-extension, and decreased ankle inversion in high-heel jogging. Collectively, these findings showed that wearing HHSs may lead to low back pain, knee osteoarthritis, and a higher risk of an ankle sprain[12].

Experimental studies have analyzed heel height and heel type during walking, running, or in other forms. Stair ascent (SA) is part of daily living and necessary for providing independence in home and community environments[13]. However, SA is difficult to maintain; it requires propelling the center of mass, horizontally and vertically. It is biomechanically challenging compared to level walking[14, 15$]$. To the authors' knowledge, no prior work has compared the biomechanical workload of SA using shoes of different heel heights and heel types. It is reasonable to hypothesize that various heel heights and heel types that provide gaits via power generation would increase the effort required to ascend stairs.

Finite element (FE) analysis could provide an effective computational framework to study anatomical structures of the foot during their interactions with the loading environment, and predict the internal stress in the foot complex in order to interpret potential risks associated with foot deformities[9, 16]. Foot-shoeground models were also developed to study the effect of different midsole plug designs on plantar pressure and the influence of varying sport ground materials on impact force during landing[17].

This study aimed to investigate the influence of HHS parameters on the pelvic position, lower extremities kinematics, GRF, metatarsal stress, and metatarsal head loading in young women during SA motion. Most shoes used for research testing were not customized for structure, style, and material. These factors result in non-negligible errors, and they affect the accuracy of the research conclusions. Thus, the shoes used in the present study were customized, which reduced human error and improved the accuracy of the research.

\section{Methods}

\section{Study participants and design}

The survey participants comprised 15 female adult volunteers (age: $20.89 \pm 3.04$ years; height: $1.61 \pm 0.05$ m; weight: $53.80 \pm 5.75 \mathrm{~kg}$; body mass index: $20.73 \pm 2.05 \mathrm{~kg} / \mathrm{m}^{2}$ ) with a foot size of 37 (European standard). Most of the participants wore HHSs once to four times per week. None of the participants reported foot-related disorders, skin lesions, or health-related problems. Signed and written consent was obtained from all participants before the experiments. The study design was approved by the Ethics Committee of Huashan Hospital. The participants were examined under seven experimental conditions: (A1) thick HHS with 3-cm heels, (A2) thick HHS with 6-cm heels, (A3) thick HHS with 8.2-cm heels, (B1) thin HHS with 3-cm heels, (B2) thin HHS with 6-cm heels, (B3) thin HHS with 8.2-cm heels, and (C) flat shoes (Figure 1). All shoes were made at the Shanghai Second Leather Shoes Factory using the same kind of material. 
A custom-made platform, with force plate, embedded staircase, was used in the study. The staircase consisted of three overall steps $(0.18 \mathrm{~m} \times 0.29 \mathrm{~m} \times 0.6 \mathrm{~m}$, height $\times$ depth $\times$ width).

The infrared 3-dimensional gait analysis system (Motion Analysis Corp., Santa Rosa, CA, USA) captured the three-dimensional trajectory data of the 25 markers affixed to the subject's bilateral anatomical landmarks. It consists of 10-mm reflective markers, eight infrared digital cameras (sampling frequency of $60 \mathrm{~Hz}$ ), a workstation and video processor, high-performance computer, an information conversion controller, and the image collection software EvaRT4.2.

Cameras were located on $10 \mathrm{~m} \times 6-\mathrm{m}$ walls at a mean height of $2.2 \mathrm{~m}$ from the floor; the direction of the cameras could be adjusted; they had a visual angle $>5680$ and a resolution $>1 / 60,000$. Force plates measuring $60 \mathrm{~cm} \times 60 \mathrm{~cm}$ (Advanced Mechanical Technology Inc., Watertown, MA, USA) were embedded in the floor. The sampling frequency was $1000 \mathrm{~Hz}$; the output voltage was $10 \mathrm{mV}$. A custom wooden staircase, without banister, was used. All data were collected by Cortex-64 5.5.0.1579 (Motion Analysis Corp.) and processed using the OthroTrak 6.6.4 research software.

Before the experiments, the participants had several minutes to get accustomed to the HHSs and were required to gradually walk along a track thrice in each pair of shoes. The positive values of joint positions in the current study referred to anterior, lateral, and proximal translation, external rotation, eversion, and dorsiflexion, whereas the negative values responded to the opposite; for peak values of kinematic data, smaller negative values represented a larger change in the direction. The range of motion (ROM) was calculated as the maximal value minus the minimum value.

FE model

Computer tomography (CT) scans (Light Speed, GE, Milwaukee, MI, USA) were acquired from the right foot of a healthy female subject wearing the flat shoes (age: 24 years, height: $160 \mathrm{~cm}$, weight: $53 \mathrm{~kg}$ ). She had no musculoskeletal pathology, previous foot surgery, or foot deformity. A custom ankle-foot orthosis was used to fix the ankle in a neutral unloaded position during CT. Scans were taken from $10 \mathrm{~cm}$ above the tibiotalar joint through the toe tip, with the thickness, in-plane resolution, voltage, current, and matrix of $0.67 \mathrm{~mm}, 0.35 \mathrm{~mm}, 120 \mathrm{kV}, 200 \mathrm{~mA}$, and $512 \times 512$ pixels, respectively. Based on the CT scan, the FE model was developed. The images were scanned at a 1-mm slice interval and had a pixel size of $0.625 \mathrm{~mm}$.

A surface model of the foot bones and skin surfaces was created using MIMICS v17.0 (Materialise, Leuven, Belgium). The surface model of the foot structures was imported into Geomagic Studio 12.0 (Geomagic, Morrisville, NC, USA) to form the solid model. Thereafter, the FE package ABAQUS v6.18 (Hibbitt, Karlsson \& Sorensen, Inc., Pawtucket, RI, USA) was used to create the FE mesh and subsequent analysis. The developed FE model consisted of 28 distinct bony segments, including the distal parts of the tibia and fibula, talus, calcaneus, cuboid, navicula, three cuneiforms, five metatarsals, 14 phalanges, 78 ligaments, and the plantar. Interactions among the bone segments were simulated as frictionless contacting bodies, whereas the surface interaction between the plantar foot and external support surface was assigned with a coefficient of friction of $0.1[18]$.

Shoe design software SolidWorks (Dassault Systemes, Waltham, MA, USA) was used to develop a 3-dimensional geometrical model of the HHSs according to the volunteer's shoe size (EU size: 37). A 6-cm heel height for the HHSs was chosen because of its high popularity and sustainability for wearers. The HHS model consisted of a 4-mm thick outsole, a 6-cm heel, 2-mm thick shankpiece, and homogenous, regularly shaped upper HHS. The material properties of each component of the HHS and foot tissues were selected from the literature and are listed in Table 1.

Simulation of SA motion with HHSs

The ground support was vertically displaced to establish contact with the shoe heel. Loading and boundary conditions for the three simulated stance instances were as follows: heel strike (29\%), midstance (57\%), and push off (73\%). They were applied accordingly for the subsequent steps[19]. The vertical GRFs were collected during SA motion with HHSs in the same subject using the Motion Analysis and Advanced Mechanical Technology force platform. For simplification, other GRFs and tibial angle components in the transverse and coronal planes were not defined. The vertical GRFs (136\%, $113 \%$, and $142 \%$ of body weight, $530 \mathrm{~N}$ ) were measured via the rigid bottom layer of the ground support for heel strike, midstance, and push off phases, respectively.

Validation of the FE shoe model

To validate the FE shoe model, the predicted plantar pressure and distribution were compared to those measured from the same subject who wore the same 6cm HHSs by using the FScan insole pressure measurement system (Tekscan Inc., South Boston, MA, USA).

Table 1. Material properties assigned to the foot tissues and HHS models

\begin{tabular}{|l|l|l|l|}
\hline Material & Element Types & $\begin{array}{l}\text { Young's } \\
\text { modulus, } \\
\text { E (MPa) }\end{array}$ & $\begin{array}{l}\text { Poisson's } \\
\text { ratio, } v\end{array}$ \\
\hline Bony & C3D6 & 7300 & 0.3 \\
\hline Soft tissue & C3D6 & 0.48 & 0.48 \\
\hline Ligaments & T3D2 & 10 & 0.3 \\
\hline Cartilage & C3D6 & 20 & 0.3 \\
\hline Shoe soles & C3D6 & 1000 & 0.42 \\
\hline Shoe heels & C3D6 & 3000 & 0.3 \\
\hline
\end{tabular}


All analyses were performed for the right side (dominant side)[20]. In order to analyze the influences of heel height and heel type on gait parameters, we used a Heel Height $\times$ Heel Type mixed analysis of variance test, with Heel Height (4 levels: control group, low [3 cm], medium [6 cm], and high [8.2 cm]) as the withingroup factor, and Heel Type (3 levels: control group, thin, and thick) as the between-group factor. For each statistical test, the significance was set at 0.05 . When the tests were significant, the least significant difference criterion was adopted for post hoc comparisons. Statistical analyses were performed with the built-in functions of SPSS 21 (IBM Corp., Armonk, NY, USA).

\section{Results}

Temporal and force parameters

One gait cycle was divided into the swing phase and the stance phase. The stance phase was represented by total support time, and was further divided into three substance phases: early stance, single limb support, and late stance phases. The early and late stance phases were phases of double support. The data were normalized to a stride period of $100 \%$ to determine the percentage of stance and swing phases in one gait cycle.

The temporal phases for SA in shoe conditions are presented in Table 1. Both stance and swing phases had significant differences due to heel types and heel heights. Increase in the heel height, resulted in greater total support time and lesser swing phase time. The same finding was observed, with respect to the heel type.

The analyzed result of the GRF variables during gait is shown in Table 2. The 1st peak vertical force (PVF) showed statistically increasing differences amongst different heel types. However, the 2nd PVF showed a significant decrease under the same conditions. There was no change in the heel height and interaction between the heel height and heel type.

Table 2 Temporal and force parameters $(n=15, P=0.05)$

\begin{tabular}{|c|c|c|c|c|c|c|c|c|c|c|}
\hline & \multicolumn{3}{|c|}{$\begin{array}{l}\text { Thick heel group } \\
\text { Mean (SD) }\end{array}$} & \multicolumn{3}{|c|}{$\begin{array}{l}\text { Thin heel group } \\
\text { Mean (SD) }\end{array}$} & \multirow[t]{2}{*}{$\begin{array}{l}\text { Flat shoe } \\
\text { Mean (SD) }\end{array}$} & \multirow{2}{*}{$\begin{array}{c}\text { Main } \\
\text { effect } \\
\text { Heel } \\
\text { type } \\
p- \\
\text { value } \\
\end{array}$} & \multirow{2}{*}{$\begin{array}{l}\text { Main } \\
\text { effect } \\
\text { Heel } \\
\text { height } \\
p- \\
\text { value } \\
\end{array}$} & \multirow{2}{*}{$\begin{array}{c}\text { Mixed anova } \\
\text { test } \\
\text { (type*height; } \\
p \text {-value } \\
\end{array}$} \\
\hline & $3 \mathrm{~cm}$ & $6 \mathrm{~cm}$ & $8.2 \mathrm{~cm}$ & $3 \mathrm{~cm}$ & $6 \mathrm{~cm}$ & $8.2 \mathrm{~cm}$ & & & & \\
\hline $\begin{array}{l}\text { Total } \\
\text { Support } \\
\text { Time } \\
(\%)\end{array}$ & $63.99(1.84)$ & $64.91(2.41)$ & $66.05(5.70)$ & $65.31(2.39)$ & $66.24(2.77)$ & $67.75(4.64)$ & $63.39(2.67)$ & $\begin{array}{c}0.008 \\
\text { bc }\end{array}$ & $\begin{array}{r}0.019 \\
¥ \& \#\end{array}$ & 0.739 \\
\hline $\begin{array}{l}\text { Swing } \\
\text { Phase } \\
(\%)\end{array}$ & $36.01(1.84)$ & $35.09(2.41)$ & $34.00(4.55)$ & $34.69(2.39)$ & $33.76(2.77)$ & $32.25(4.19)$ & $36.61(1.79)$ & $\begin{array}{c}0.016 \\
\text { bc }\end{array}$ & $\begin{array}{l}0.043 \\
¥ \& \#\end{array}$ & 0.862 \\
\hline $\begin{array}{l}\text { Double } \\
\text { Support } \\
\text { Time } \\
(\%)\end{array}$ & $15.70(5.89)$ & $14.77(3.06)$ & $16.25(5.48)$ & $14.86(1.51)$ & $14.72(2.36)$ & $15.34(2.55)$ & $14.38(2.01)$ & 0.436 & 0.535 & 0.878 \\
\hline $\begin{array}{l}\text { 1st peak } \\
\text { vertical } \\
\text { force } \\
(\mathrm{N} / \mathrm{BW})\end{array}$ & $53.26 \square 16.16 \square$ & $54.60 \square 15.84 \square$ & $54.84 \square 16.00 \square$ & $55.03 \square 15.86 \square$ & $56.07 \square 15.52 \square$ & $55.97 \square 16.96 \square$ & $50.83 \square 17.37 \square$ & $\begin{array}{c}0.019 \\
\mathrm{abc}\end{array}$ & 0.125 & 0.992 \\
\hline $\begin{array}{l}2 \text { nd } \\
\text { peak } \\
\text { vertical } \\
\text { force } \\
(\mathrm{N} / \mathrm{BW})\end{array}$ & $60.27 \square 5.17 \square$ & $59.09 \square 5.71 \square$ & $58.02 \square 4.96 \square$ & $62.53 \square 4.73 \square$ & $61.94 \square 5.97 \square$ & $60.95 \square 6.28 \square$ & $64.48 \square 4.31 \square$ & $\begin{array}{c}0.027 \\
\text { ac }\end{array}$ & 0.424 & 0.969 \\
\hline
\end{tabular}

$¥$ Statistically significant difference between control group and medium heeled group.

\& Statistically significant difference between control group and high heeled group.

\# Statistically significant difference between low heeled group and high heeled group.

a Statistically significant difference between control group and thick heeled group.

b Statistically significant difference between control group and thin heeled group.

c Statistically significant difference between thick heeled group and thin heeled group.

Kinematic findings

Page $4 / 14$ 
Significant differences in the joint angles were detected across some musculoskeletal conditions (Table 3). With respect to joint angles in the sagittal plane, an increase in the heel height resulted in increased ankle ROM and decreased knee ROM values, respectively. This was seen across all groups. For the pelvic joint, the thin-heeled group exhibited significantly greater ROM values, compared to the control and the thick-heeled groups. However, no significant differences were detected for the hip joint.

For joint angles in the transverse plane, an increase in the heel height resulted in an increase in the pelvis ROM and a decrease in the ankle ROM values, respectively. However, no significant differences were detected for the hip and the knee joints.

In the frontal plane, only the ankle ROM values significantly decreased with an increase in the heel height.

Table 3 Range of motion parameters $(n=15, P=0.05)$

\begin{tabular}{|c|c|c|c|c|c|c|c|c|c|c|c|}
\hline & \multicolumn{3}{|c|}{$\begin{array}{l}\text { Thick heel group } \\
\text { Mean (SD) }\end{array}$} & \multicolumn{3}{|c|}{$\begin{array}{l}\text { Thin heel group } \\
\text { Mean (SD) }\end{array}$} & \multirow[t]{2}{*}{$\begin{array}{l}\text { Flat shoe } \\
\text { Mean (SD) }\end{array}$} & \multirow{2}{*}{$\begin{array}{c}\text { Main } \\
\text { effect } \\
\text { Heel } \\
\text { type } \\
p \text { - } \\
\text { value }\end{array}$} & \multirow{2}{*}{$\begin{array}{c}\text { Main } \\
\text { effect } \\
\text { Heel } \\
\text { height } \\
p \text { - } \\
\text { value }\end{array}$} & \multirow{2}{*}{$\begin{array}{c}\text { Mixed ano' } \\
\text { test } \\
\text { (type*heigl } \\
p \text {-value }\end{array}$} \\
\hline & & $3 \mathrm{~cm}$ & $6 \mathrm{~cm}$ & $8.2 \mathrm{~cm}$ & $3 \mathrm{~cm}$ & $6 \mathrm{~cm}$ & $8.2 \mathrm{~cm}$ & & & & \\
\hline \multirow[t]{4}{*}{$\begin{array}{l}\text { Transverse } \\
\text { plane }\end{array}$} & Pelvis & $9.41(2.76)$ & $11.37(2.15)$ & $11.44(2.26)$ & $9.82(2.15)$ & $11.37(3.03)$ & $12.06(2.22)$ & $9.51(2.63)$ & 0.396 & $\begin{array}{l}0.003 \\
¥ \&^{*} \#\end{array}$ & 0.966 \\
\hline & Hip & $14.4(3.12)$ & $13.5(3.04)$ & $12.97(4.22)$ & $14.06(4.41)$ & $13.83(4.05)$ & $12.98(3.05)$ & $14.16(3.53)$ & 0.988 & 0.419 & 0.943 \\
\hline & Knee & $16.87(5.79)$ & $16.47(5.43)$ & $15.74(6.06)$ & $16.80(5.90)$ & $16.45(4.27)$ & $14.69(5.61)$ & $17.42(5.70)$ & 0.746 & 0.500 & 0.920 \\
\hline & Ankle & $6.61(2.30)$ & $5.15(2.40)$ & $3.92(1.65)$ & $6.56(2.51)$ & $5.00(1.84)$ & $3.96(1.52)$ & $9.28(3.20)$ & 0.946 & $\begin{array}{l}0.034 \\
\S ¥ \& \#\end{array}$ & 0.896 \\
\hline \multirow{4}{*}{$\begin{array}{l}\text { Frontal } \\
\text { plane }\end{array}$} & Pelvis & $16.13(3.23)$ & $16.27(3.88)$ & $16.84(3.53)$ & $16.13(3.31)$ & $16.39(3.41)$ & $17.38(4.16)$ & $15.91(3.11)$ & 0.764 & 0.524 & 0.953 \\
\hline & Hip & $15.55(3.46)$ & $15.35(4.19)$ & $15.70(3.52)$ & $15.47(3.42)$ & $15.50(3.48)$ & $15.43(3.68)$ & $15.62(3.10)$ & 0.928 & 0.988 & 0.974 \\
\hline & Knee & $11.33(2.46)$ & $10.58(3.84)$ & $10.64(2.76)$ & $11.27(3.84)$ & $10.66(3.54)$ & $10.53(3.11)$ & $9.54(2.01)$ & 0.753 & 0.689 & 0.991 \\
\hline & Ankle & $16.43(3.45)$ & $16.97(4.59)$ & $14.38(3.71)$ & $16.45(3.01)$ & $16.94(3.50)$ & $14.75(3.35)$ & $14.49(2.13)$ & 0.958 & $\begin{array}{c}0.016 \\
\# \%\end{array}$ & 0.998 \\
\hline \multirow[t]{4}{*}{$\begin{array}{l}\text { Sagital } \\
\text { plane }\end{array}$} & Pelvis & $7.39(2.18)$ & $7.36(1.56)$ & $8.35(2.93)$ & $8.49(2.76)$ & $8.59(2.50)$ & $9.36(2.53)$ & $7.20(2.25)$ & $\begin{array}{c}0.026 \\
b c\end{array}$ & 0.204 & 0.995 \\
\hline & Hip & $58.75(4.15)$ & $58.08(5.10)$ & $57.61(4.87)$ & $58.65(4.35)$ & $57.69(4.50)$ & $57.47(4.16)$ & $59.91(3.81)$ & 0.824 & 0.585 & 0.991 \\
\hline & Knee & $89.30(5.76)$ & $87.82(4.18)$ & $84.67(2.99)$ & $89.20(4.70)$ & $86.07(4.98)$ & $84.11(3.39)$ & $89.09(3.75)$ & 0.383 & $\begin{array}{l}0.000 \\
\& * \# \%\end{array}$ & 0.749 \\
\hline & Ankle & $35.57(5.64)$ & $38.22(5.50)$ & $39.34(7.02)$ & $35.00(5.24)$ & $38.07(5.96)$ & $39.12(6.81)$ & $33.47(6.35)$ & 0.809 & $\begin{array}{l}0.039 \\
¥ \& \#\end{array}$ & 0.990 \\
\hline
\end{tabular}

$\S$ Statistically significant difference between control group and low heeled group.

$¥$ Statistically significant difference between control group and medium heeled group.

\& Statistically significant difference between control group and high heeled group.

* Statistically significant difference between low heeled group and medium heeled group.

\# Statistically significant difference between low heeled group and high heeled group.

\% Statistically significant difference between medium heeled group and high heeled group.

b Statistically significant difference between control group and thin heeled group.

c Statistically significant difference between thick heeled group and thin heeled group.

With respect to heel heights, the major differences in the peak joint angle occurred at the pelvic, knee, and ankle joints (Table 4). Increase in the heel height induced knee flexion, ankle external and internal rotation, and ankle pronation, but reduced pelvic external rotation, knee external rotation, ankle dorsiflexion, 
and ankle plantarflexion. For ankle joints in the sagittal plane, increased heel height demonstrated reduced values of plantarflexion and dorsiflexion. Larger dorsiflexion was seen when compared between the control group and the low-heeled group.

Table 4 Mean maximum peak angle (degrees) $\quad(n=15, P=0.05)$ 


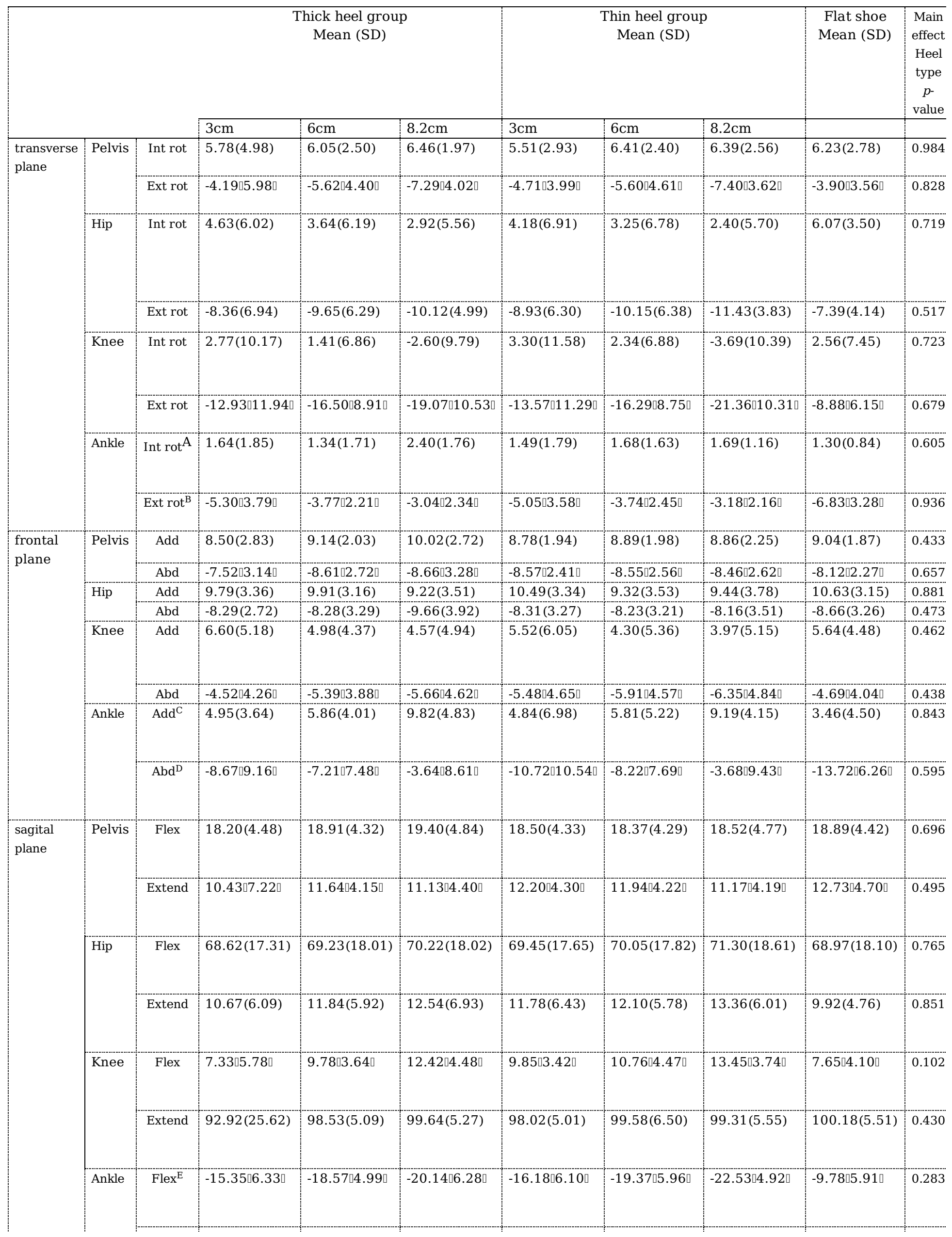




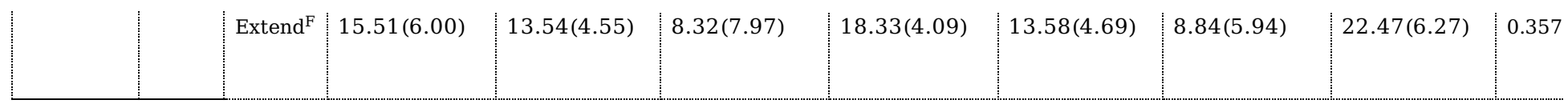

$\S$ Statistically significant difference between control group and low heeled group.

$¥$ Statistically significant difference between control group and medium heeled group.

\& Statistically significant difference between control group and high heeled group.

* Statistically significant difference between low heeled group and medium heeled group.

\# Statistically significant difference between low heeled group and high heeled group.

$\%$ Statistically significant difference between medium heeled group and high heeled group.

a Statistically significant difference between control group and thick heeled group.

b Statistically significant difference between control group and thin heeled group.

c Statistically significant difference between thick heeled group and thin heeled group.

A inversion for ankle.

B eversion for ankle

C valgus for ankle.

D varus for ankle

E Plantarflexion for ankle.

F Dorsiflexion for ankle

Findings from the FE model

During heel strike, peak plantar pressure was almost located at the center of the heel. The pressurized area was concentrated at the heel, ball of the foot, and toes during midstance. At push off, the heel and midfoot were unloaded and the peak plantar pressure at the forefoot was intensified. The FE predicted interfacial pressures including plantar and 1st metatarsal pressures during SA walking conditions are tabulated in Table 5. The von Mises stress in the 1st metatarsal pressure generally increased because of the decreased heel base area in three simulated stance instances, as shown in Figure 3 .

Table 5 The measured plantar pressure and first metatarsal pressure during simulated heel strike, midstance and push off (A: thick heel shoes B: thin heel shoe)

\begin{tabular}{|c|c|c|c|c|c|c|}
\hline & \multicolumn{3}{|c|}{ Thick heel group } & \multicolumn{3}{|c|}{ Thin heel group } \\
\hline & heel strike & mid stance & push off & heel strike & mid stance & push off \\
\hline Planar Pressure(MPa) & 0.33 & 0.31 & 0.46 & 0.41 & 0.33 & 0.46 \\
\hline First metatarsal(MPa) & 24.99 & 16.46 & 33.27 & 24.97 & 18.08 & 40.10 \\
\hline
\end{tabular}

\section{Discussion}

Temporal and force parameters

Heel height and heel type influence the temporal phases and the GRF parameters, respectively. When comparing the effect on force parameters by wearing HHS during SA, a thin heel showed an increase in the 1st PVF and a reduction in the 2nd PVF. This increase may have resulted from an exaggerated ankle plantarflexion[21], similar to the study in which the peak utilized coefficient of friction increased, during high-heeled walking, and increased significantly as the heel area became smaller[12, 22]; heel height in our study had no effects, and this may be due to the different walking conditions.

When comparing the effect on temporal phases by wearing HHSs during SA, a high-heeled shoe with a thin heel showed an increase in the total support time and reduced swing phase. Participants seemed to gain stability by increasing the stance phase, especially while wearing HHSs with a thin heel type. No interactions between age and heel height were significant on temporal parameters. 
The most prominent finding in the present study was that HHSs restricted the ankle ROM in the transverse plane and in the frontal plane, which is consistent with that in a previous study[12]. However, there was an increase in the ankle dorsiflexion-plantarflexion in the sagittal plane as the increased heel height aligned the foot in plantarflexion. For decreased knee flexion-extension and rotational ROM, the increase of heel height is usually associated with a higher knee flexion moment; knee flexion in flat shoes is similar to that in another HHS study for SA walking between young and elder women[23]. Moreover, the increased values of pelvic ROM in the transverse and sagittal planes may compensate for this condition. Other postural effects of HHSs were also mentioned in the literature, for example, increased transversal pelvic rotation and pelvic anteversion[9, 24].

As the ROM of the lower extremity could be affected by the participant's height and stair dimensions, it seems to adjust to different stair dimensions by varying the flexion/extension at the knee rather than the ankle or the hip[25]. In this study, the major changes occurred in the transverse and the sagittal planes, rather than the frontal plane. As walking with balance on stairs is complicated, it is likely to observe less movements in the transverse and sagittal planes for the altered foot mechanism. The reduced ROM of the ankle and knee at increased heel height, except for the ankle in the sagittal plane, could be explained as an adaptation to control the joints from having excessive motion. With a greater heel height, we observed a ROM increase in the sagittal plane, as a less effective lever for the application of muscle force to the ground, and a probable factor for muscle fatigue.

Peak joint value

Heel height, rather than heel type, had a greater impact on the peak joint value overall. With high heels, we observed an increased internal rotation of the pelvis, external rotation of the knee, inversion and plantar flexion, and flexion of the knee, with decreased ankle eversion, varus, and dorsiflexion.

Consistent results based on the techniques have revealed that high heels cause an increase in the plantar curve angle, and hence a decrease in the dorsiflexion angle[26]. It is reported that high-heeled shoes lead to a larger ankle inversion, as compared to flat shoes; knee flexion peak also increases in level walking[27].

Increased knee flexion may lead to increased quadriceps forces and proximal anterior tibial shear force, both of which are causes of anterior cruciate ligament strain[28]. Previous studies also reported that excessive knee extension and rectus femoris activity, induced by knee flexion[11], are major factors for knee overload. Increased external rotation of the knee may disrupt the weight distribution, and contribute to the development of knee osteoarthritis[29].

From the viewpoint of ankle biomechanics, HHS with increased ankle plantarflexion and reduced dorsiflexion, resulting in greater joint movement in the mediolateral and diagonal directions, are less stable than low-heeled shoes[30]. An increase in the heel height is linked to increased ankle inversion and reduced eversion. As a result, some of the shock-absorbing function of eversion is lost; the increased load needs to be attenuated, either by changes in kinematics, or direct absorption, by the soft tissues. This carries a high risk of injury due to variation in the joint contact area and stress distribution[31, 32]. With a more flexible ankle, consistent with the previous study, HHS mainly affects the rotational motion of the ankle complex during walking. The abnormal position of the talocrural joint, the decrease in the subtalar joint ROM during the gait in HHS[33], and the compensation by altered kinematics, e.g., increased ROM at the proximal joints, could be the reasons for HHS resulting in a larger pelvic rotation and tilt change. This study has the limitation that the effects observed, for aged HHS wearers, were not studied sufficiently.

\section{Plantar von Mises stress and 1st metatarsal joint loading}

For the plantar pressure during heel strike and midstance, values increased with a small heel base area and were almost the same at push off. According to a previous study, the distribution of plantar pressure changes with various heel heights and becomes more medial and anterior in HHSs. Interestingly, for the 1st metatarsal joint, the pressure was almost the same between the thick and thin heel groups because loading was mainly on the heel during heel strike. Additionally, from midstance during forefoot weight bearing, the stress became larger and reached its peak value at push off stance. A previous HHS study reported that peak pressures increased by $30 \%$ to $40 \%$ at the forefoot, and pressure shifted to the medial forefoot, especially the 1 st metatarsal head and the hallux with HHS wearing[34]. Our study observed that with a small heel area, peak pressures increased by $7 \%$ to $20 \%$ at the 1 st metatarsal area, and obviously for the 1 st metatarsal head. This increased metatarsal stress may cause metatarsalgia while sustaining weight bearing, hallux valgus, and different kinds of soft tissue-related diseases or discomfort, such as callus and bunions[35].

\section{Conclusions}

In order to stabilize body posture during SA when wearing HHSs with a small heel base area, compensatory changes to drive an effective motor response include increasing pelvic ROM in the transverse plane and sagittal plane and changing the joint angles of the lower extremities. In addition, larger plantar von Mises stress and 1st metatarsal joint loading may lead to some injuries in the clinical setting. Further study maybe aim at experienced difference.

\section{Abbreviations}

stair ascent (SA)

high-heeled shoe (HHS)

ground reaction forces (GRFs)

Finite element (FE)

Range of motion (ROM)

Computer tomography (CT)

Peak vertical force (PVF) 


\section{Declarations}

Ethics approval and consent to participate

The study design was approved by the Ethics Committee of Huashan Hospital. Signed and written consent was obtained from all participants before the experiments.

Consent for publication

Signed and written consent was obtained from all participants before the experiments.

Availability of data and materials

Competing interests

Funding

Authors' contributions

Data curation, jiangyinzi shang,; Formal analysis, shuiqiang zhang; Methodology, xin ma;

Writing - review \& editing, alan yan.

\section{References}

1. Yoon JY, An DH, Yoo WG, Kwon YR: Differences in activities of the lower extremity muscles with and without heel contact during stair ascent by young women wearing high-heeled shoes. Journal of orthopaedic science : official journal of the Japanese Orthopaedic Association 2009, 14(4):418-422.

2. Titchenal MR, Asay JL, Favre J, Andriacchi TP, Chu CR: Effects of high heel wear and increased weight on the knee during walking. J Orthop Res 2015, 33(3):405-411.

3. Esenyel M, Walsh K, Walden JG, Gitter A: Kinetics of high-heeled gait. J Am Podiatr Med Assoc 2003, 93(1):27-32.

4. Al-Abdulwahab SS, Al-Dosry RD: Hallux valgus and preferred shoe types among young healthy Saudi Arabian females. Ann Saudi Med 2000, 20(3-4):319321.

5. Barnish MS, Barnish J: High-heeled shoes and musculoskeletal injuries: a narrative systematic review. Bmj Open 2016, 6(1).

6. Frey C: Foot health and shoewear for women. Clin Orthop Relat Res 2000(372):32-44.

7. Menz HB, Morris ME: Footwear characteristics and foot problems in older people. Gerontology 2005, 51(5):346-351.

8. Michonski J, Witkowski M, Glinkowska B, Sitnik R, Glinkowski W: Decreased Vertical Trunk Inclination Angle and Pelvic Inclination as the Result of MidHigh-Heeled Footwear on Static Posture Parameters in Asymptomatic Young Adult Women. Int J Env Res Pub He 2019, 16(22).

9. Schroeder J, Hollander K: Effects of high-heeled footwear on static and dynamic pelvis position and lumbar lordosis in experienced younger and middleaged women. Gait Posture 2018, 59:53-57.

10. Weitkunat T, Buck FM, Jentzsch T, Simmen HP, Werner CM, Osterhoff G: Influence of high-heeled shoes on the sagittal balance of the spine and the whole body. Eur Spine J 2016, 25(11):3658-3665.

11. Mika A, Oleksy L, Mika P, Marchewka A, Clark BC: The influence of heel height on lower extremity kinematics and leg muscle activity during gait in young and middle-aged women. Gait Posture 2012, 35(4):677-680.

12. Gu Y, Zhang Y, Shen W: Lower extremities kinematics variety of young women jogging with different heel height. International Journal of Biomedical Engineering and Technology 2013, 12.

13. Harper NG, Wilken JM, Neptune RR: Muscle Function and Coordination of Stair Ascent. J Biomech Eng 2018, 140(1).

14. Koyama Y, Tateuchi H, Araki K, Fujita K, Umehara J, Kobayashi M, Ichihashi N: Mechanical energy efficiency for stepping up and down in persons with medial knee osteoarthritis. Gait Posture 2019, 69:143-149.

15. Lee HJ, Chou LS: Balance control during stair negotiation in older adults. J Biomech 2007, 40(11):2530-2536.

16. Budhabhatti SP, Erdemir A, Petre M, Sferra J, Donley B, Cavanagh PR: Finite element modeling of the first ray of the foot: a tool for the design of interventions. J Biomech Eng 2007, 129(5):750-756.

17. Gu YD, Li JS, Lake MJ, Zeng YJ, Ren XJ, Li ZY: Image-based midsole insert design and the material effects on heel plantar pressure distribution during simulated walking loads. Comput Methods Biomech Biomed Engin 2011, 14(8):747-753.

18. Zhang M, Mak AF: In vivo friction properties of human skin. Prosthet Orthot Int 1999, 23(2):135-141.

19. Yu J, Cheung JT, Wong DW, Cong Y, Zhang M: Biomechanical simulation of high-heeled shoe donning and walking. J Biomech 2013, 46(12):2067-2074.

20. B MH: Two feet囚 or one person? Problems associated with statistical analysis of paired data in foot and ankle medicine. The Foot 2004, $14(1): 2 \otimes 5$.

21. Hong WH, Lee YH, Chen HC, Pei YC, Wu CY: Influence of heel height and shoe insert on comfort perception and biomechanical performance of young female adults during walking. Foot Ankle Int 2005, 26(12):1042-1048.

22. Park S, Park H, Park J: Effect of heel base area and walking speed on the utilized coefficient of friction during high-heeled walking. Work 2019, 64(2):397405. 
23. Hsue BJ, Su FC: Kinematics and kinetics of the lower extremities of young and elder women during stairs ascent while wearing low and high-heeled shoes. J Electromyogr Kines 2009, 19(6):1071-1078.

24. Dai M, Li X, Zhou X, Hu Y, Luo Q, Zhou S: High-heeled-related alterations in the static sagittal profile of the spino-pelvic structure in young women. Eur Spine $J$ 2015, 24(6):1274-1281.

25. Livingston LA, Stevenson JM, Olney SJ: Stairclimbing kinematics on stairs of differing dimensions. Archives of physical medicine and rehabilitation 1991, 72(6):398-402.

26. Simonsen EB, Svendsen MB, Norreslet A, Baldvinsson HK, Heilskov-Hansen T, Larsen PK, Alkjaer T, Henriksen M: Walking on High Heels Changes Muscle Activity and the Dynamics of Human Walking Significantly. J Appl Biomech 2012, 28(1):20-28.

27. Di Sipio E, Piccinini G, Pecchioli C, Germanotta M, lacovelli C, Simbolotti C, Cruciani A, Padua L: Walking variations in healthy women wearing high-heeled shoes: Shoe size and heel height effects. Gait \& Posture 2018, 63:195-201.

28. Fleming BC, Renstrom PA, Ohlen G, Johnson RJ, Peura GD, Beynnon BD, Badger GJ: The gastrocnemius muscle is an antagonist of the anterior cruciate ligament. $J$ Orthopaed Res 2001, 19(6):1178-1184.

29. Kerrigan DC, Lelas JL, Karvosky ME: Women's shoes and knee osteoarthritis. Lancet 2001, 357(9262):1097-1098.

30. Wu WL, Rosenbaum D, Su FC: The effects of rocker sole and SACH heel on kinematics in gait. Med Eng Phys 2004, 26(8):639-646.

31. Yung-Hui L, Wei-Hsien H: Effects of shoe inserts and heel height on foot pressure, impact force, and perceived comfort during walking. App/ Ergon 2005, 36(3):355-362

32. Payne C, Munteanu S, Miller K: Position of the subtalar joint axis and resistance of the rearfoot to supination. J Am Podiatr Med Assoc 2003, 93(2):131135.

33. Wang C, Geng X, Wang S, Ma X, Wang X, Huang J, Zhang C, Chen L, Yang J, Li J et al: The impact of high-heeled shoes on ankle complex during walking in young women-In vivo kinematic study based on 3D to 2D registration technique. J Electromyogr Kinesiol 2016, 28:7-16.

34. Martinez-Nova A, Sanchez-Rodriguez R, Perez-Soriano P, Llana-Belloch S, Leal-Muro A, Pedrera-Zamorano JD: Plantar pressures determinants in mild Hallux Valgus. Gait Posture 2010, 32(3):425-427.

35. Pique-Vidal C, Sole MT, Antich J: Hallux valgus inheritance: pedigree research in 350 patients with bunion deformity. J Foot Ankle Surg 2007, 46(3):149154.

\section{Figures}




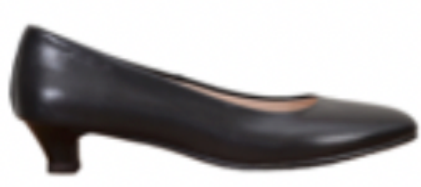

A1

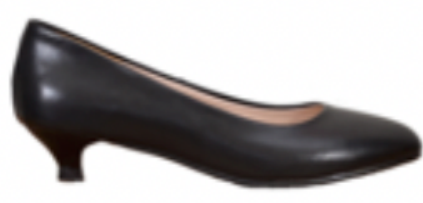

B1

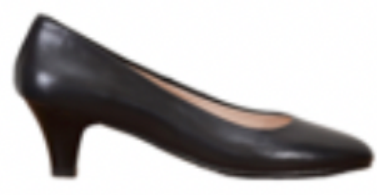

A2

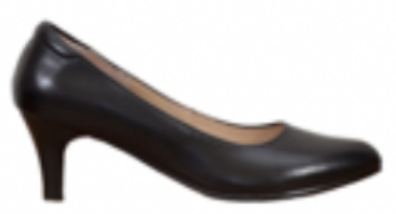

B2

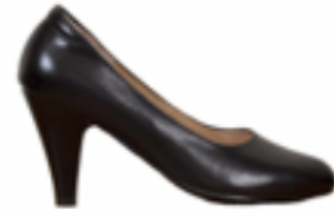

A3

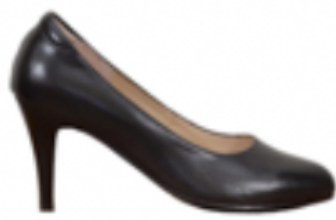

B3

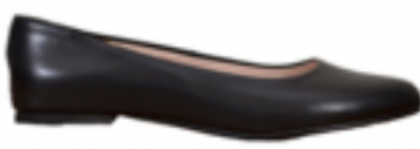

C

\section{Figure 1}

experimental conditions: (A1) thick heel HHS with 3-cm heels, (A2) thick heel HHS with 6-cm heels, (A3) thick heel HHS with 8.2-cm heels, (B1) thin heel HHS with 3-cm heels, (B2) thin heel HHS with 6-cm heels, (B3) thin heel HHS with 8.2-cm heels, and (C) flat shoes 


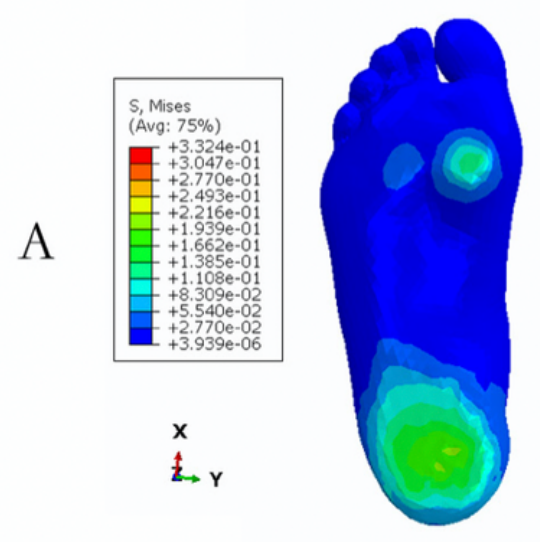

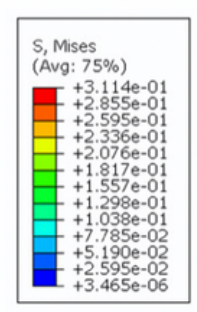

$x$
$b$

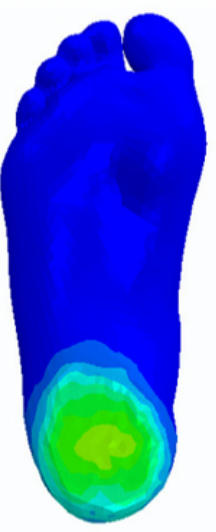

Heel strike

$x$
$t_{\mathbf{w}}$
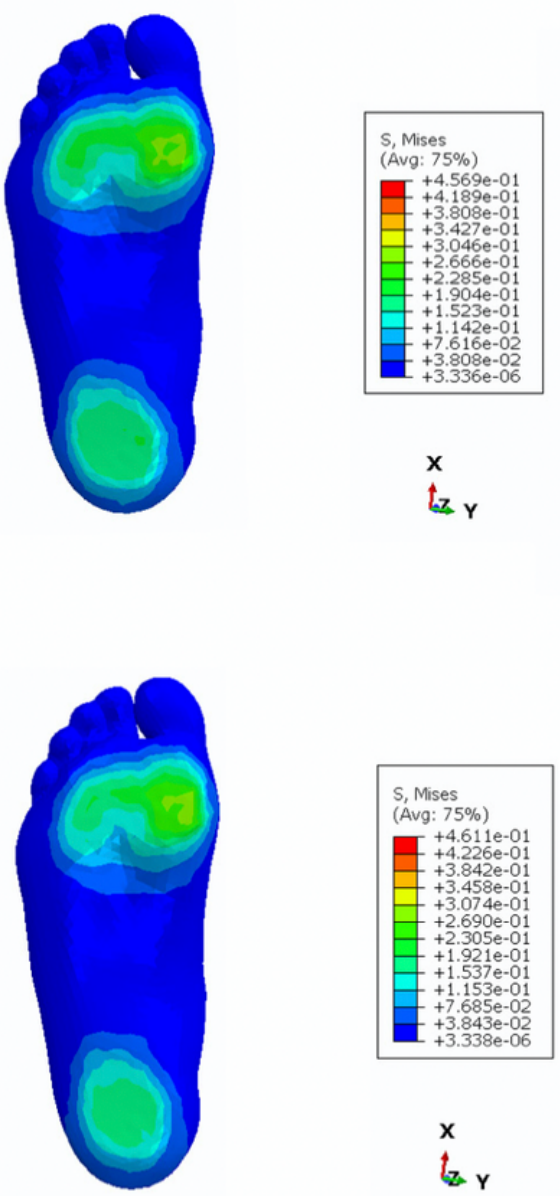

Mid stance x tz $y$

$\mathrm{Z}_{\mathbf{Y}}$

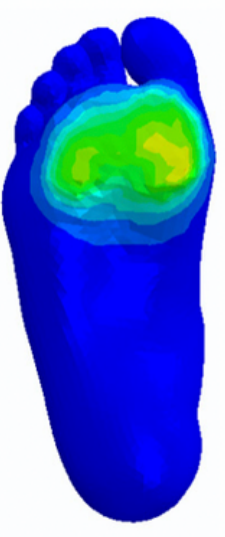

\section{Push off}

\section{Figure 2}

The deformed plots of HHS and foot during simulated heel strike, midstance and push off (A: thick heel shoes B: thin heel shoe) 
A
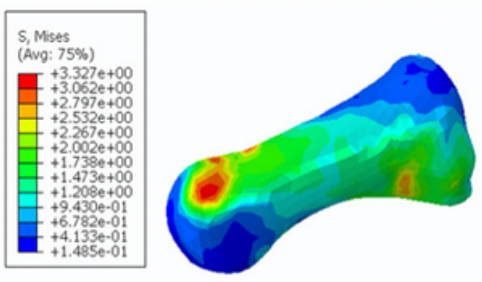

$\operatorname{lor}_{x}$

$\mathrm{B}$
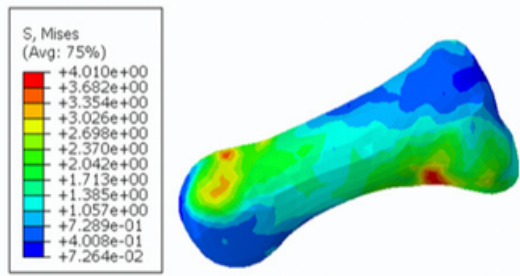

tor

Heel strike
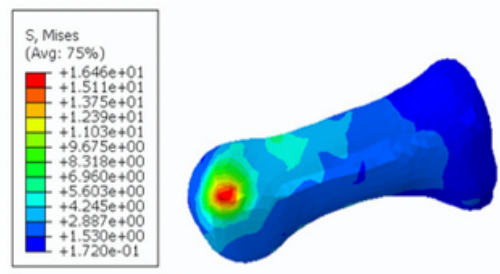

$\sum_{x}^{z}$
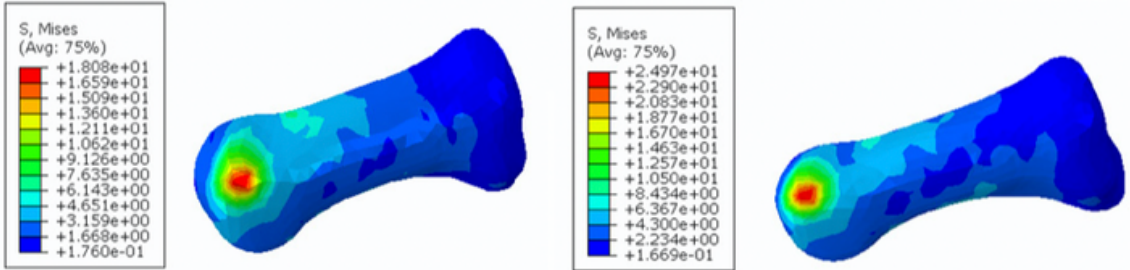

$\sum_{X}^{z}$

Mid stance
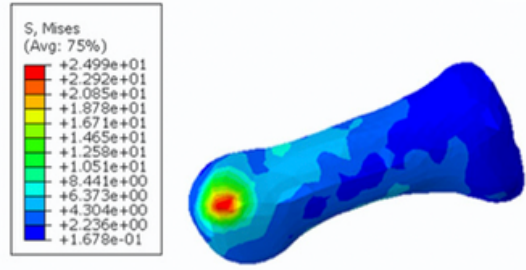

$\operatorname{s}^{z}$

$S^{2}$

Push off

\section{Figure 3}

The measured first metatarsal pressure during simulated heel strike, midstance and push off (A: thick heel shoes B: thin heel shoe)

\section{Supplementary Files}

This is a list of supplementary files associated with this preprint. Click to download.

- supplementaryFEMODEL.docx 